\title{
المستويات اللغوية في المعاجم الحديثة بين المحافظة والتطوّر
}

\author{
بجاور سيد بجاور سكران \\ megawer2000@gmail.com \\ كبير باحثين - مجمع اللغة العربية بالقاهرة
}

\begin{abstract}
Abstrak
Sarjana Arab sejak masa klasik sampai masa modern menaruh perhatian kepada disiplin ilmu leksikografi Arab. Perhatian kepada ilmu leksikografi yang sangat membantu pengguna dan penutur aktif bahasa Arab ini tampak sejak era Khalil bin Ahmad (786 M.) yang menulis kamus Al-'Ain sampai masa Ahmad Mukhtar Umar (2003) dengan kamusnya Mu'jamu al-Lughah al-'Arabiyyah al-Mu'āshirah. Studi linguistik modern kemudian menghasilkan level bahasa (language levels) yang ditemukan pada kamuskamus Arab. Level bahasa ini tentu berbeda dalam pandangan para leksikograf Arab. Sebagian melihatnya dari perspektif level bahasa yang mencakup sintaksis, morfologi dan fonologi yang banyak diacu oleh kamus-kamus klasik dan modern. Sebagian yang lain memandang level bahasa berupa ragam bahasa ammiyyah (al-'ämmī/colloquial Arabic) dan ragam bahasa asing (al-a jamilforeign language). Kedua ragam ini mendapat perhatian dari kamus-kamus Arab melalui sejumlah penjelasan baik secara eksplisit atau implisit yang ada dalam kamus-kamus tersebut. Level bahasa juga mencakup bahasa khazanah (turāts) karya sastra yang dinilai sebagai landasan dasar bagi para pengguna dan pengkaji bahasa. Selain turāts, level bahasa lisan yang digunakan sehari-hari juga ditemukan dalam kamus-kamus Arab. Level bahasa ini mengalami perubahan artikulasi pada sejumlah kosakata dalam bentuk perubahan tanda baca (charakat). Artikel ini menguraikan empat level bahasa tersebut oleh kamus-kamus Arab modern dengan tujuan untuk menunjukkan sejauh mana kamus Arab modern memanfaatkan paradigma leksikografi Arab klasik dan kontribusinya terhadap pengembangan deskripsi kosakata bahasa untuk penutur bahasa saat ini dan pengguna kamus Arab modern.
\end{abstract}

Kata Kunci: level bahasa, leksikografi Arab, Mu'jamul Lughah Al-'Arabiyyah Al$M u ' a ̄ s h i r a h$, pengembangan kosakata.

\begin{abstract}
Arabic scholars from the classical to the modern period paid attention to the disciplines of Arabic lexicography. A great attention was given to lexicography, which was fundamentally helpful for active users and speakers of the Arabic language since the era of Khalil bin Ahmad (786 AD) who wrote the Al-'Ain dictionary to Ahmad Mukhtar Umar's (2003) period with his dictionary Mu'jamu al-Lughah al-'Arabiyyah alMu'âshirah. Modern linguistic studies then produce language levels found in Arabic dictionaries. This level of language is certainly different in the view of Arab lexicographers. Some see it from the perspective of a language level that includes syntax, morphology and phonology, mostly referred to by classical and modern dictionaries. Some others see the language levels typically a variety of languages ammiyyah (al'àmmī/colloquial Arabic) and various foreign languages (al-a jamì/foreign language).
\end{abstract}


Both of these varieties have seized the attention of Arabic dictionaries through a number of explanations either explicitly or implicitly in these dictionaries. Language levels additionally includes the treasure of language (turäts) literary works are assessed as the basic foundation for language users and reviewers. In addition to turäts, the level of spoken language used daily is also found in Arabic dictionaries. This language level undergoes articulation changes in a number of vocabularies in the form of changes at the vowel marks (charakat). This article outlines these four levels of language by modern Arabic dictionaries which aim to show the extent to which modern Arabic dictionaries make use of the classical Arabic lexicography paradigm and its contribution to the development of descriptions of language vocabulary for current language speakers and modern Arabic dictionary users.

Keywords: language levels, Arabic lexicography, Mu'jamulLughah Al-'Arabiyyah AlMu'āshirah,vocabulary development.

$$
\text { خلال اتّفاق الدراسات المعجمية الحديثة على أن }
$$

المعجمية العامة تتفرع إلى معجمية عـامة نظرية توافق

الحديثـة

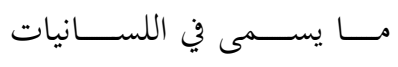

ومعجمية عامة تطبيقية توافق ما "Lexicologie"

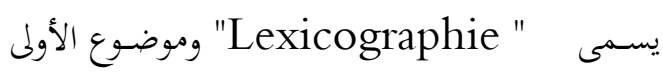

البحث في الوحدات المعجمية من حيث مكوناتها-

كالانتمـاء المقولي والتأليف الصوتي والبنية الصرفية-

وأصولها واشتقاقها ودلالاتها، وموضوع الثانية البحث

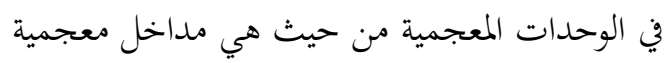

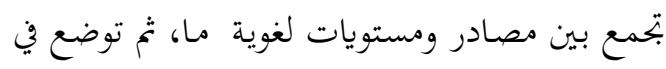

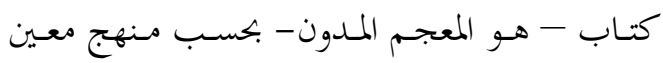

يتقيّد به المؤلف في ترتيب المداخل وتعريفها.

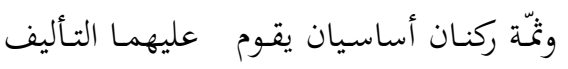

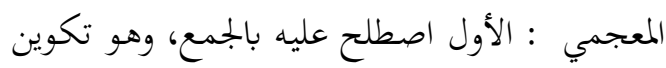

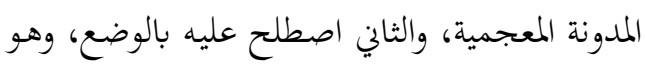

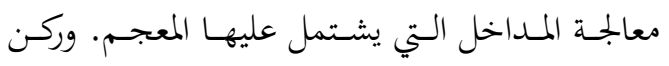

الجمع في المعجم يقوم على أسّين :أولمما اصطلح عليه

بالمستويات اللغوية، وثانيهما اصطلح عليه بالمصادر.

والمستويات اللغوية في المعجم العربي - من وجهة نظر

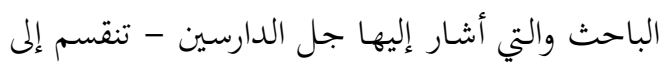

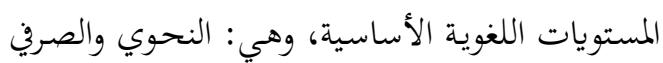

مما لا شكَّ فيه أن الدراسات المعجمية لم تحظ

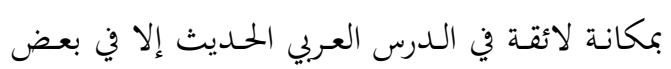

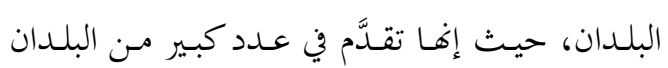

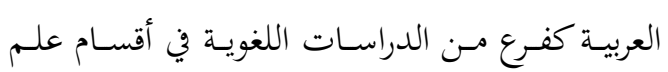

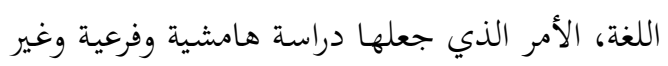

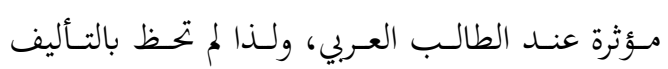

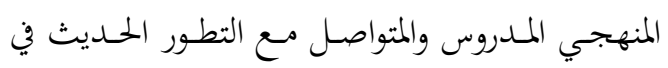

هذا العلم الذي لا ينكر أهميته أحد.

وعلى الرغم مـن إيلاء العرب القـدماء عناية لهـية

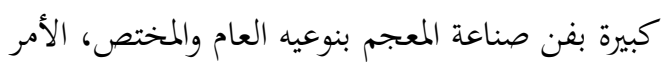

الذي يدلُّ دلالة واضحة على حاجة مستخدمي اللغة

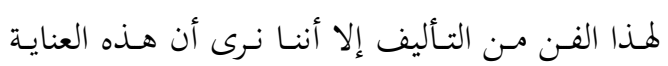

بالمعجمى قـــــترت في العصـور الوسيطة، التي كـان

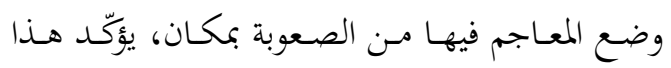

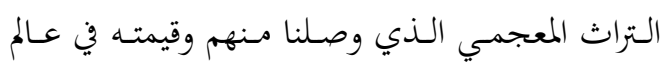

المعجمات العربية، وقد شهد القرن العشرون نشاطًا

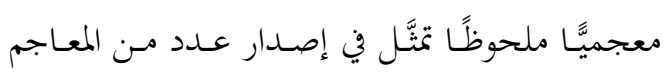

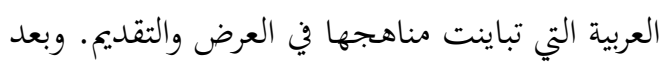

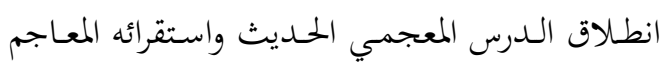

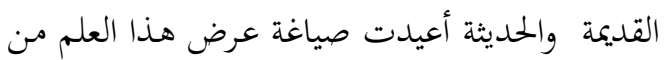


القديمة والحديثة أها تعتمد على بعضها، وأن بعضها

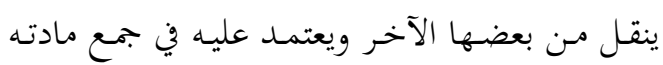

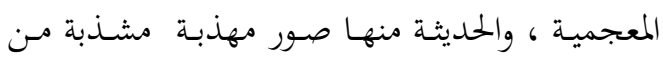

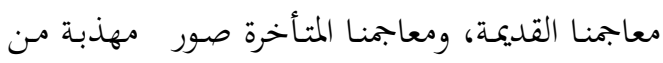
المعاجم الحديثة المتقدمة عليها.

\section{المعاجم الحديثة ومناهج وضعها.}

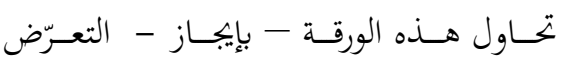

لاستخدام المعاجم الحديثة لمذه المستويات من خلال استعراض عدد من مناهج هذه المعجمات في محاولة

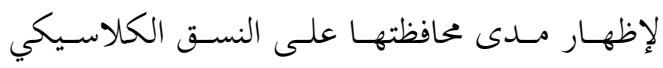
القديم، وما أسهمت به من تطوُرِ في عرض اللغة بما

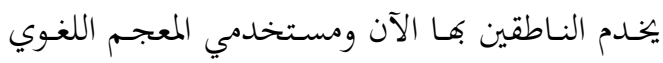
الحديث، وذلك من خلال استعراض مناهج ستة من

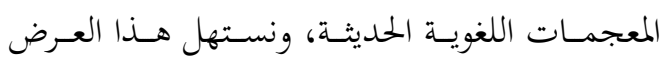

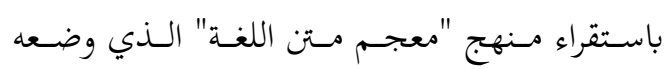
العلامة اللغوي الشيخ أحمد رضا، استجابة لاقتراحِ من المجمـع العلمـي العربي بدمشـق ( بجمـع اللغـة العربيـة بدمشق - الآن) وصدر في ستينيات القرن العشرين؛ وأوضحَ منهج عملهِ من خلال النقاط الرئيسية التالية:

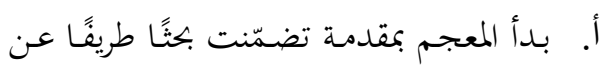

$$
\text { نشأة اللغة وتطورها. }
$$

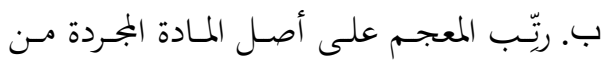
الزيادات في الحروف، كما هو الحال في سائر

$$
\text { معاجم اللغة العربية قديمها وحديثها. }
$$

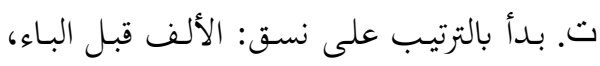

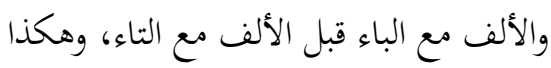

$$
\text { في ثالث الحروف منها. }
$$

ث. ذكـر مصـادر الفعـل الثلاثـي كلّهـا؛ لأفهـا. سماعية ليس لها ضابط مطّرد. أمّا مصادر

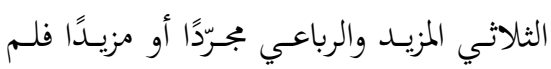
تذكر اكتفاءً بعلم القارئ ( وقد وضع المؤلف تردي
والصوتي وهي المستويات التي تعتمدها المعاجم قديكها

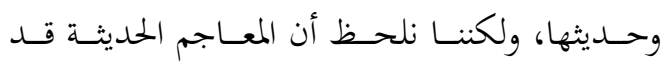
ابتعدت بعض الشيء عن تقصي هذا كما حاولت أن تفعل المعاجم القديمة. ومهن المستويات اللغوية أيضًا

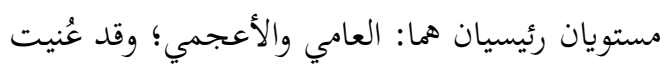

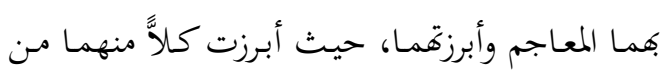

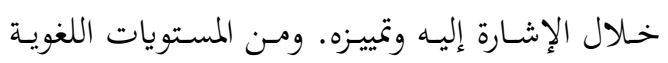

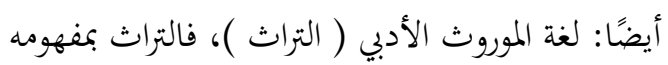

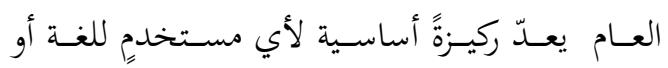

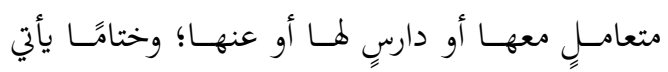
مستوى اللغـة البسـيطة اليوميـة، وهي لغـة النـاطقين

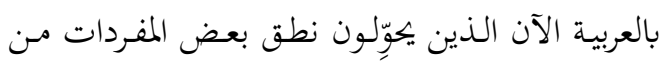
خلال تعديل ضبط حروف الكلمة.

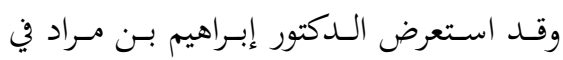

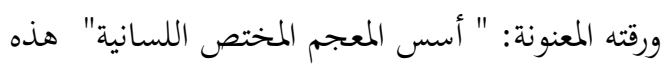

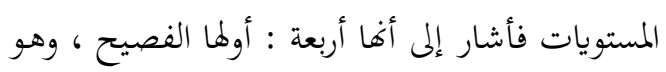

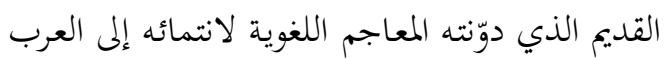

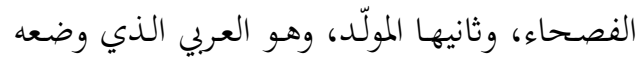

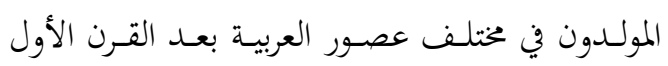
الهجري خاصة؛ وثالث المستويات هو العامي، وهو

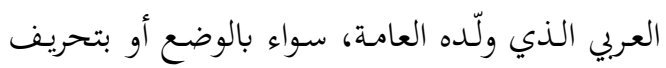

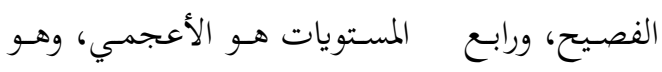

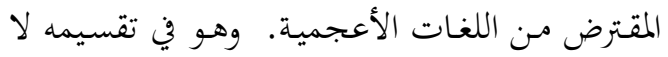

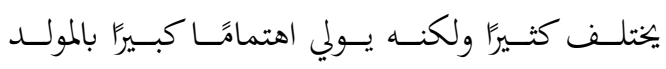

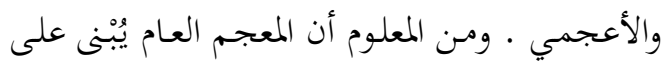
رصيد لغوي مستقر هو الذي دونته المعاجم القديمة في الغالب، لذا فإن العربية الحديثة - بدوالها ومدلولاتحا المستحدثة- مازالت ضعيفة المنزلة في معاجمنا اللغوية العامة الحديثة؛ وهذا ما سنلحظه من خلال استعراض مناهج المعجمات الحديثة التي تتعرض لها هذه الورقة. حيث إنـا نلاحظ مـن خـلال استخدامنا للمعاجم 


$$
\begin{aligned}
& \text { ض. ذكر المؤلف كل المواد المذكورة في معجمي } \\
& \text { لسان العرب وتاج العروس، وقد حرص على لمونى } \\
& \text { ألاَّ تفوته أية مادة. }
\end{aligned}
$$

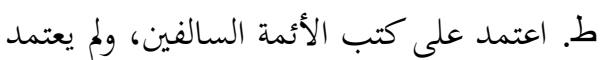$$
\text { كتب المتأخرين المعاصرين لأها غير مأمونة }
$$

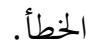$$
\text { ظ. لم يـذكر اصطلاحات العلوم والفنون؛ لأهـا }
$$$$
\text { خارجة عن اللغة من وجهة نظره، إلا ما كان }
$$$$
\text { منها له أساس بالمتن. }
$$

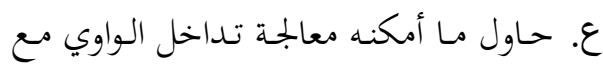$$
\text { اليائي في المعتل الأجوف والناقص من خلال }
$$$$
\text { تصور تحكمه البنود التالية: }
$$

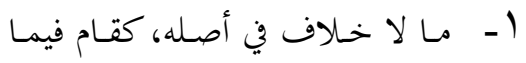$$
\text { أصله الواو، وباع فيما أصله الياء }
$$

Y- - مـا صح عندهم مجيئه واويَّا أو يائيَّا

بمعنى واحد، وهذا الضرب أكثر من

$$
\text { أن يجصى في كلامهم. }
$$$$
\text { ك- ما اختلفوا في أصله. }
$$$$
\text { ع - ماس استعمل في معنيين متفرعين مـن }
$$

$$
\text { أصل واحد. }
$$

0- - مـا لم يظهر لهم أصله فحملوه على

أحد الوجهين أو أجازوه فيهما معًا.

وقد جرى المؤلف على جعل ما كان من

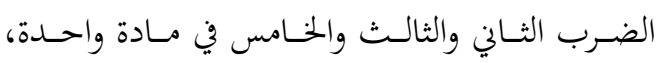

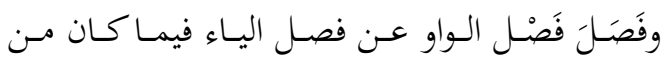

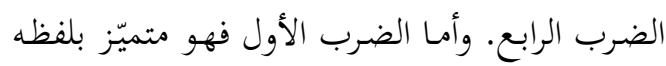

ومعناه. وقد أحصى المؤلف في جدولٍ الكلمات التي

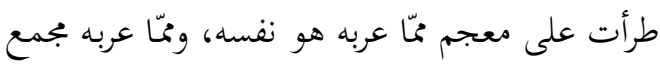

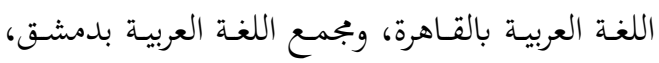

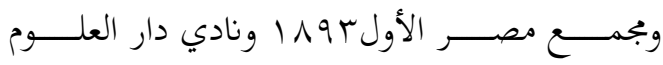

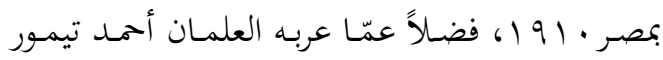

جدولاً للمصادر المطّردة يستحضر الطالب

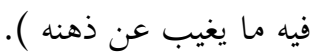

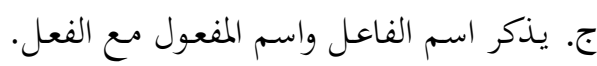

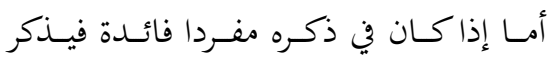

مفردا.

ح. ذكر النسب الشاذة، ونبّه على شذوذها. ولم

يذكر القياسية إلا فيما ندر.

خ. أشار إلى ضبط حركة عين المضارع.

د. ذكر الجمـوع مـا استطاع؛ لأهـا في الثلاثي

سماعية في الأغلب، ليس لها ضابط مطرّد.

ذذ. عند اختلاف الأئمة في تفسير الكلمة اختير

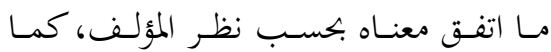

تجنب سرد أقوال الأئمة في الاستدلال مراعاة

لأن القارئ لا يطلب غير معنى الكلمة.

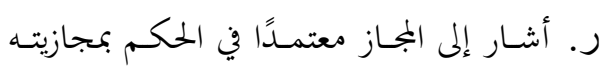

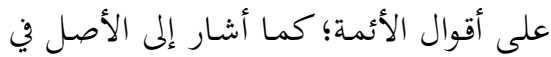

معنى الكلمة معتمدًا على نصوصهم أيضًا.

ز. إذا عثر على كلمـة نادرة نادّة عـن مادهَـا،

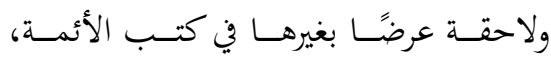

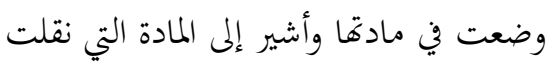

$$
\text { منها لمراجعتها. }
$$

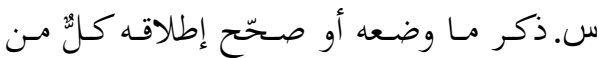

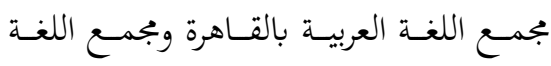
العربية بدمشق حتى إصدار معجمه.

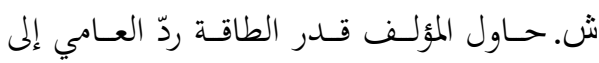

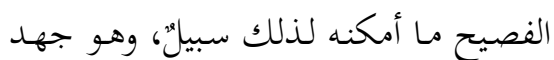

ميّز يحتاج للدرس والتأمّل والاستكمال.

ص. ذكــــ الكلمــات الـتي طـرأت في العصـــ

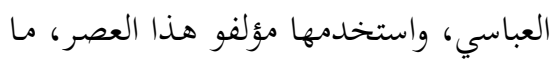
اندثر منها وما بقي في الاستعمال. 
يعتمــد عليهـا وعـزّزت ذلـك بالاستشـهـاد بالآيات القرانية والأحاديث النبوية والأمثال العربية والتراكيب

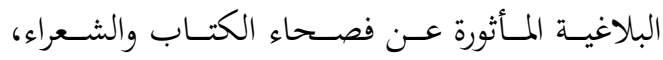

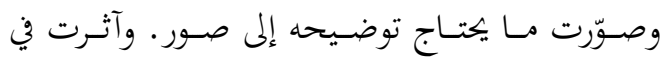

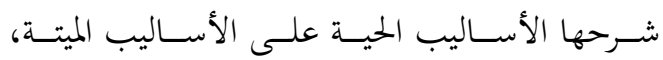
وأدخلت في متن المعجم ما دعت الضرورة إلى إدخاله

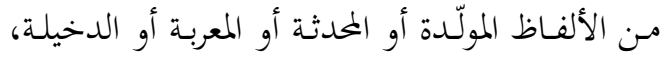
التي أقرها المجمع، وارتضاها الأدباء. ويتلخّص المنهج في ترتيب المواد فيما يلي: ا - تقديم الأفعال على الأسماء.

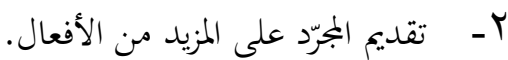

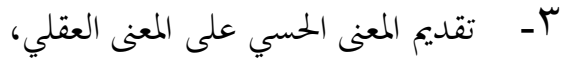
والحقيقي على المجازي.

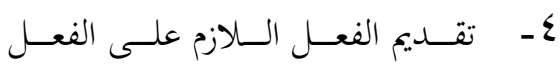
المتعدي.

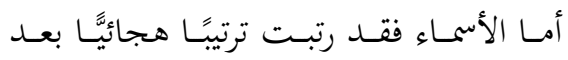
ترتيبها في المادة.

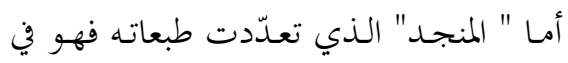

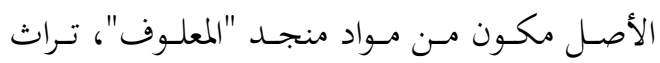

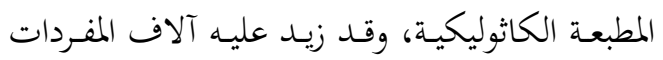

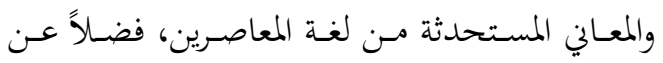

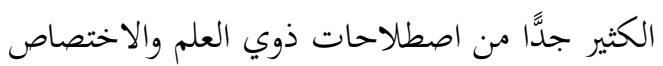
بمختلف ميـادين المعرفـة، وقـد تنـاول القـائمون عليه الكثـير مـن الكلمــات القديمـة والحديثـة بالإيضـاح

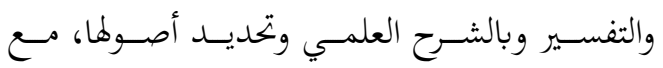
اجتهادهم في ذكر اللغة الأم التي ينتمي إليها الكلام الدخيل، إضافة إلى تعيين حقول المعرفة التي تستعمل

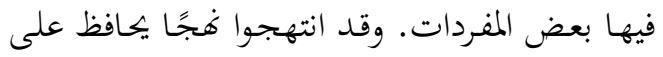

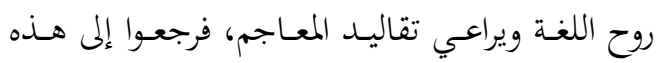

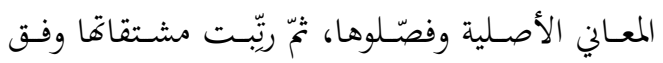
الطريقة التقليدية.
المصري وأنستاس الكرملي. كما ضمّن مقدّمة معجمه عددًا من الجداول المفيدة، هي: - - مصادر القياسية للأفعال المزيدة.

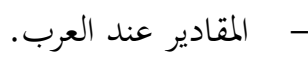

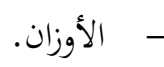
- - - مقاييس. - - جداول الأوزان والمكاييل. - - مدول المساحة.

وقد حرص الباحثث على استعراض مقدمـة

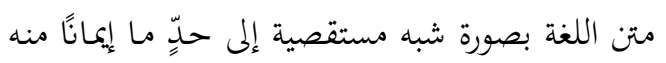
بأن جميع المعاجم التالية له لم تزد على منهجهـ شيئًا بل كان هو الأكمل في الاستقصاء والمعالجة.

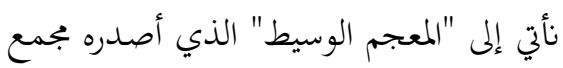

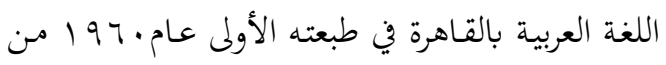
القرن العشرين، وتوالت طبعاته، وقد استقبله الدارسون

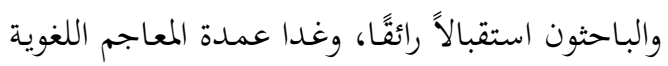

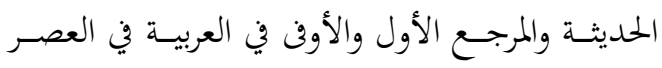

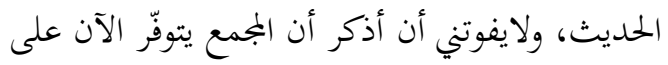

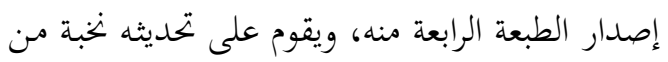

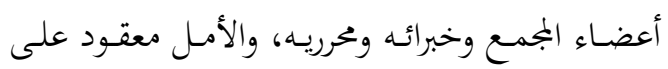
إخراجه في القريب بإذن الله. أمـا عن مـنهج الوسيط ولهيط

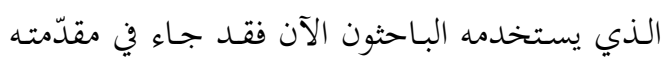

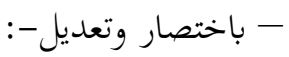
أهملـت اللجنــة كثـيرًا مـن الألفــاظ الحوشـية الجافية، أو التي هجرها الاستعمال لعدم الحاجة إليها،

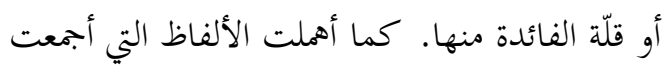
المعـاجم على شـرحها بعبـارات تكـاد تكسون واحـدة،

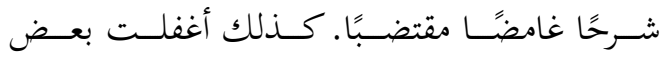
المترادفات التي تنشأ عن اختلاف اللهجات؛ وعنيت

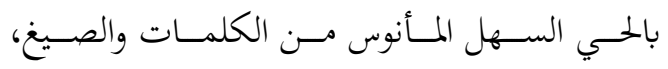
واستعانت في شرحها للألفاظ بالنصوص والمعاجم التي 
منهجيته بما يمكِّن المنتفعين به من استعماله في سهولة

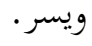

وقـــ تضـمنت هـــه المنهزيـة القواعـد الـتي جعلت الأسـاس لترتيب مواده والقواعد التي تتبع في

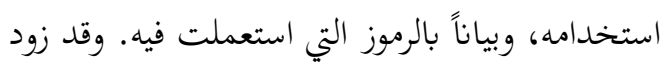

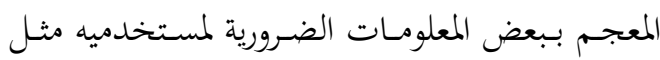
النظام الصريف في اللغة العربية، مما هو ذو صلة وثيقة

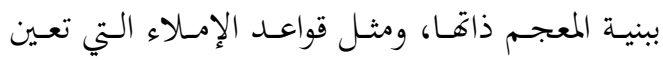

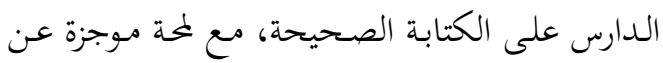
اللغة العربية وطرائق تنميتها. هـذا ويعـد المعجـم العـربي الأساسي، بخواصهـ ومميزاته، حصيلة جهد جماعي، ندبت المنظمة له نخبة

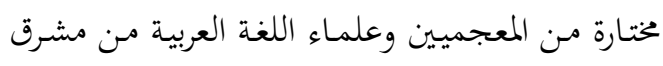
الـوطن العـربي ومـن مغربـه، مــن فقهـوا اللغـة العربيـة

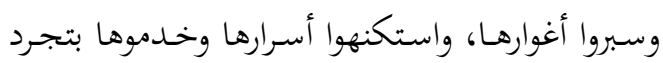
واقتدار من العلماء العرب المعجميين في الوطن العربي، وفي خارجه؛ وممن جمعوا إلى ذلك ممارسة تربوية، وقد

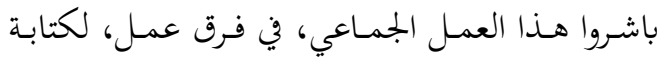
المعجم، ولمراجعته وللتنسيق بين موضوعاته، ثم لتحريره

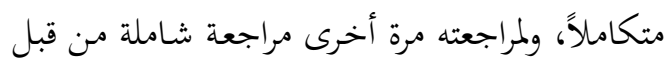
أساتذة متخصصين، حتى استقام.

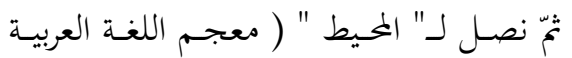

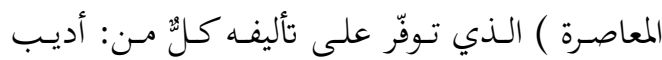

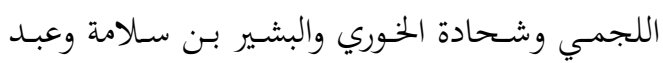
اللطيف عب ونبيلة الرزاز، وقدّم له أيضًا محيي الدين

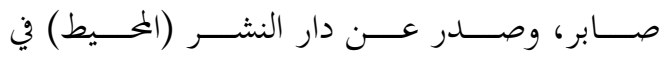
العامبر99 19 ـ ولهذا المعجم ومنهجهـ خصوصية تفرّد بها على كل معاجم العربية القديمة والحديثة، حيث إنه. يتبنى ترتيب مفرداته ترتيبًا ألفبائيًا، ومنها تيسير الرجوع مباشرةً إلى الكلمة المراد معرفة معناها، ومنها احتواؤه

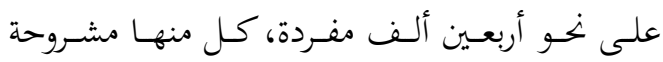

ونعرض الآن لمنهج " المعجم العربي الأساسي"

الذي أصدرته المنظمة العربية للتربية والثقافة والعلوم التهري

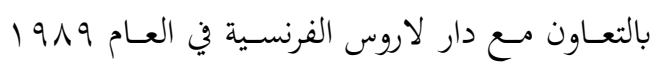

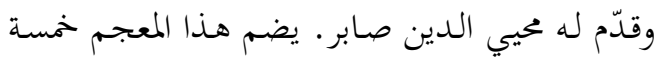

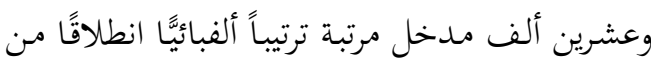
جذر الكلمة، مفسرة بدقة وإيجاز، ومعززة بالشواهد

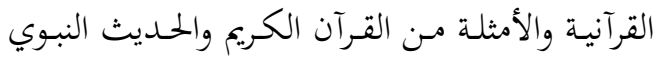
الشريف والأمثال والعبارات السياقية ولغة المعاصرة.

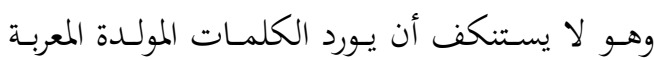

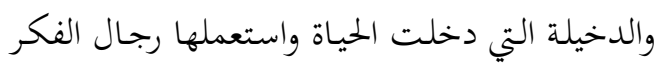
والثقافة وأقرقا المجامع اللغوية العربية، على أنه يتجنب دحبن

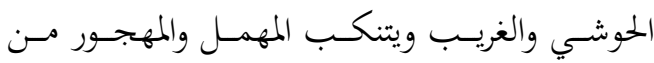

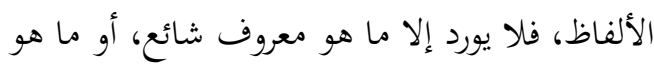
جدير بأن يعرف من مفردات اللغة الجارية على ألسنة

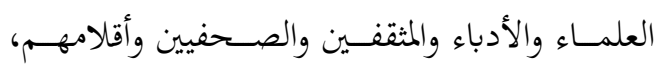
والمبسوطة في المؤلفات والبحوث والدراسات العربية. هـذا ولمعجــم سمــة موسـوعية محـدةد، فهو

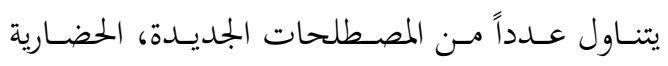
والعلميـة والتقنيـة، ويتعرض في إيجـاز إلى طائفة كبيرة

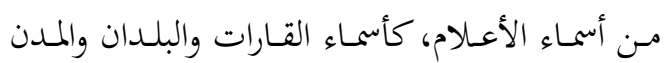

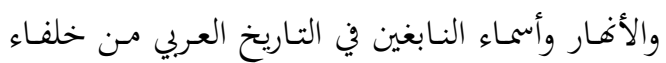
وقادة وفقهاء وعلماء وشعراء وفنانين....إلخ. ويتميز هذا المعجم، في إطار وظيفته الأولى، وهي تيسير تعليم

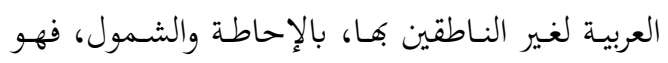
يضم كل ما يحتاج إليه مستعمله، فوسعت مادته كثيراً

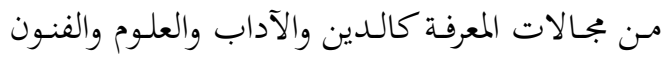
والإعلام، من خلال اللغة الفصيحة الحية والمستعملة، في هذا العصر في الوطن العربي الكبير مع الإشارات في بعض المواضع إلى استعمالات قطرية خاصة، وهو

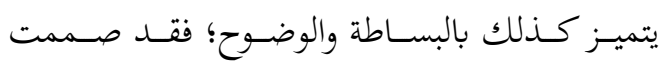


السابقين، إنَّا ضمَّ إليها مادة غنيَّة بالكلمات

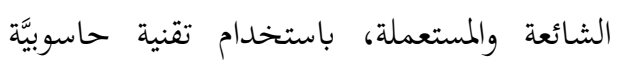

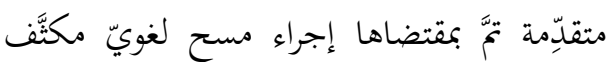

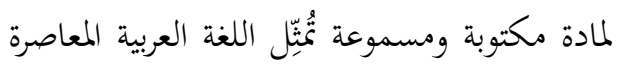
أصدق تمثيل، فقد تميَّزت بالمعاصرَة والسياقات المستعملة، بالإضافة إلى الاستعمالات الجديدة التي ترد في سياق مألوف للدى المستخدم، وتتجاوز في حجمها مئة مليون كلمة ومثال ـ وقد ملاف

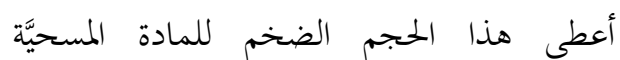
صلاحية الحكم على كلمةٍ بالشيوع؛ ومن تئَّ إدخالها في المعجم، أو بعدم الشيوع؛ ومن تئَّ إهمالها وحذفها من المعجم (ويصدق هذا على

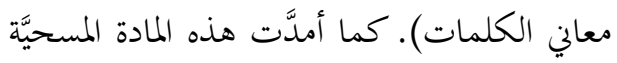
القائمين بالعمل بكل المصاحبات اللفظية لأية

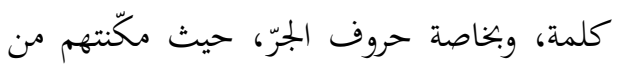
معرفة أكثر الاستعمالات شهرة وكذلك تتبع أنماطها الأكثر استعمالاً. كما أمدَّةمَ بمعلَّل تكرار

ولعلّ أكثر ما يميز هذا المعجم هو توسعه في جملة من الأقيسة، على النحو التالي:

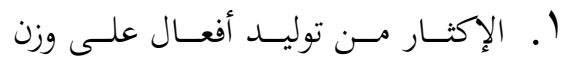
"فعَل "، أو "فوعـل"، أو "فعلـن" لإفـادة

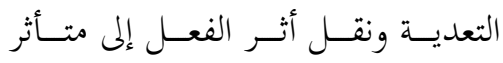

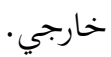
r. الإكثار من استخدام المصدر الصناعي،

$$
\text { وجمع الجمع. }
$$

r. النسـب بزيادة الألف والنون أو بـزيادة

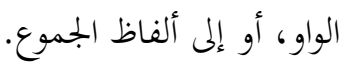

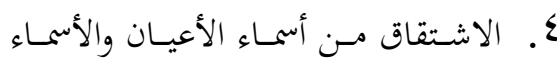
المزيدة.
بأسلوب واضح، مرفوقة باستشهاد من آيات القرآن

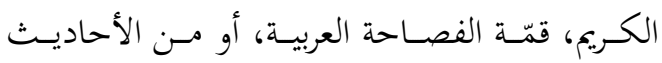

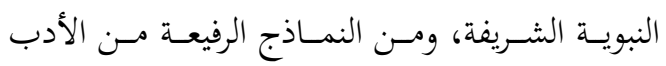

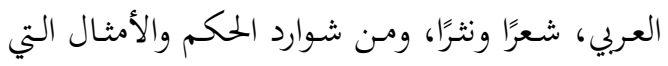
تتضمن خبرة الأمة العربية وحكمتها، وقيمها العالية في الحياة؛ هذا إلى إمتاع القارئ وزيادة معارفه بالصور

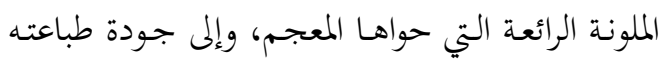
وإخراجه.

ونغتم جولتنا بـ " معجم اللغة العربية المعاصرة "

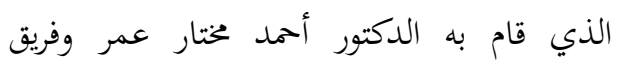
عمله، وصدر عن عالم الكتب بالقاهرة في العام

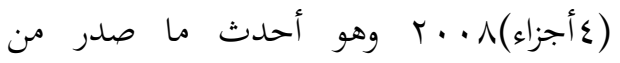

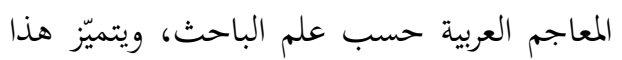
المعجم بأنه معجم عصري يقف على الكلمات

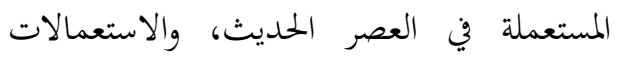
المستحدثة التي لمُ تفقد الصحة اللغويَّة، كما يغطِّي معظم الاستعمالات الخاصَّة بجميع أقطار الدول

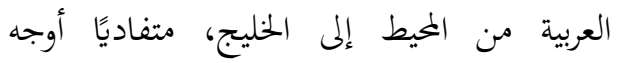

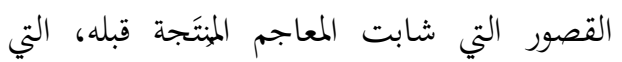
تتلخَّص فيما يأتي: 1-الخلط بين المهجور والمستعمَل، وغياب كثيرٍ من المستحدَث. Y-اعتماد بعض المعاجم على بعض، دون تمحيص أو تدقيق. r-القصور في تناول المعلومات الصرفية والدلالية لمداخلها. ـ -عدم إثبات معظم المصاحبات اللفظية التي يكثُر استخدامها، وكذلك التعبيرات السياقية التي اكتسبت معانيَ جديدة زائدة على معاني مفرداتما. وقد حاول هذا المعجم تجنّب عيوب الأعمال السابقة عليه من خلال عدم اعتماده على معاجم 
" وإذا انقاد غير اللغة العربية من اللغات مع

مرتّي المعاجم على حروف الكلمة كما هي في أصلها

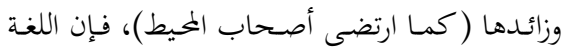

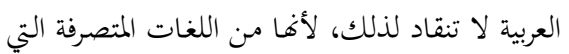
تسدخل في صـلبها الـزيادات علـى المـادة لـزيادة في

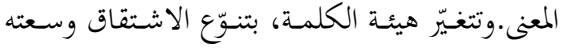
وكثرته، تنوّعًا يبعث الشتات في الكلمات المشتقّة من فينه أصل واحد إذا أريد ترتيبها على صورتها، ويدعو إلى لي

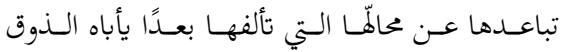
العربي. كـأكرم وكرّم، فـالأولى تكـون حينئـدٍ في أوّل

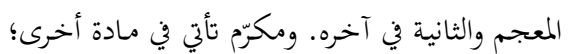
وكـذلك التكـريم، وهـو مصـدر كرّرم، يجيء في غـير مادقَا. ومثل ذلك: ودّع وأودع واتدع وايتدع وتودّع

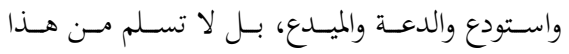

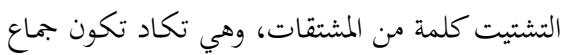
اللغة.

وكذلك يأخذ بعض الحروف أكثر الكلمات إليه كحرف الألف مثلاً فإنّه يحتضن في شتّى فصوله

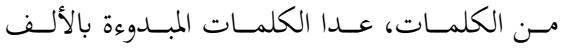
الأصلية، كل الكلمـات المزيدة ألفًا في أوّلها، وصليّة كانـت أو قطعيـة، كأفعل وافتعـل وانفعـل واسـتفعل

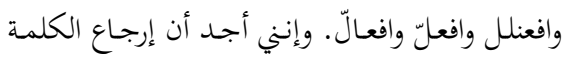
إلى أصولها للاطلاع على معناهـا في المعجم هو مـن ونس

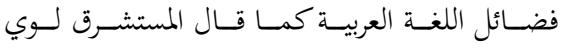
ماسنيون: " وقد وجدنا خصائص في اللغات السامية ولا سيما العربية، فبإن فيها فضائل خاصـة بهـا دون سـواها، منهـا : الأصـول الثلاثيـة في الكلمـات، أي إرجـاع أي كلمـة كانـت إلى ثلاتــة أحسرف للاطـلاع

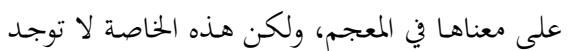

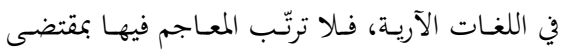
أصول الكلمات بل ترتّب كل كلمة كما تلفظ." .

وبعـد؛ فـإن مـن يريـد أن يجمـل اللغـة العربيـة السـامية على منـاهج غيرهـا مـن اللغـات الآريـة، مـع تباين مـا بينها مـن الخصائص والمزايا والمقوّمات، هو كمن يطلب في الماء جذوة نار.
0. معاملـة بعــض المركّبـات الإضـافيّة أو

الوصفيّة معاملة الألفاظ المفردة...إلخ.

وآخر ما يتميز به هذا المعجم هو صدوره في

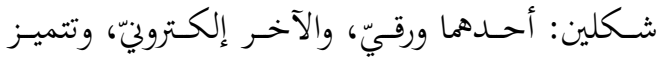
النسـخة الورقيـة بوجـود أربعـة فهـارس، كمـا تتميـز النسـخة الإلكترونيـة بالإمكانات الهائلة في استـدعاء

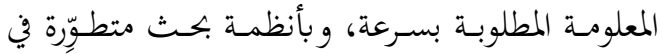
كافة جزئيَّات المعجم، حيث يمكن لمستخدم النسخة الإلكترونية البحث عن أيّة كلمة أو عبارة في المعجم.

\section{المستويات اللغوية بين الححافظة والتطور.}

كان عرضنا المتواضع والمقتضب لنمـاذج من

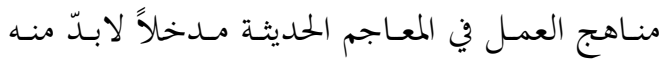
للولوج إلى طرق معالجتها للمستويات اللغوية، حيث تتضمّن هذه المناهج كيفية إعداد هذه المعاجم وكيفية

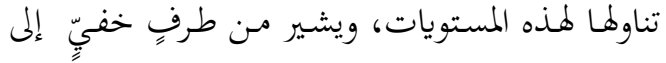
أن هذه المعاجم قد تخلّصت تمامًا من أسلوب العرض القـــيم الـذي تبـنى في أوّل الأمــــ الترتيـب بحسـب المخارج الصوتية كمـا هو عند الخليل وغيره، والنظام الدائري كما هو عند ابن فـارس في المقاييس، ونظام القافيـة كمــا هـو في جـلّ المعـاجم القديمـة - لتتبـنى النظـام الألفبـاتي العـادي في كـل المعـاجم تقريبّا، وفي حسين ظـلّ ويبقـى الجـــر اللغـوي هـو عمــاد المـادة

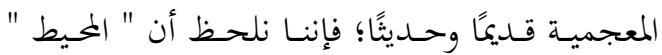
الذي أعدّه أديب اللجمي وآخرون قد ارتضى ترتيب مفرداته ألفباتيًّا متخليًا لأوّل مرة عن الجذر أو الأصل اللغوي، وهم بهذا أوّل مـن عامل اللغة العربية معاملة

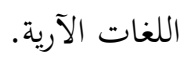

وأجـدي مضطرًا للاستشـهاد بمـا قالهه الشيخ أحمد رضـا في مقدمته لـ"متن اللغة" في سياق الدفاع عـن الترتيـب المعجمسي للمــاخل في المعـاجم العربيـة بحسب الأصل أو الجذر، حيث يقول: 
ومعجــم اللغـة العربيـة المعاصـرة " فهـي كمــا تشـير عناوينها قد صرفت جلٌ اهتمامها إلى اللغة المعاصرة، وأهملت اللغة التراثية إهمالاً جسيمًا يؤخذ عليها ويحدّ مـن استفادة المتعـاملين معهـا، حيـث إن اللغـة العربية من وجهة نظرنا وحدة واحدة لا فكاك منها فنحن إلى الآن نقرأ الكتب القديمة وعمدتنا فيها القرآن الكريم والـتراث النبـوي الشـريف والكتـب الصـحاح وأمهات كتب التراث التي تزخر بمادة لغوية كبيرة أهملتها هذه المعاجم ساعية وراء القـارئ الحـديث متناسية مـا يمثله ذلك من انبتات للصلة بين العربي وتراثه الزاخر. ولعل قفـزة " المحيط " التي انفــد مـن خلالهـا بترتيـب مفرداتـه ترتيبًا ألفباتئَا مهمـالًا الأصل الثلاثي للجذر اللغوي العربي أكبر ثورة على المعاجم العربية قـديمها وحـديثها على السـواء، وهـو أمـر يشـق على مستخدمي المعاجم العربية، وإن رحّب به - ولا أظنّ ذلك قد حدث- غير العرب أو المستشرقون المحدثون. وبنظرة متأنية إلى المستويات اللغوية في المعاجم الحديثة نلحظ أن مؤلّفي هذه المعاجم قد بذلوا جهودًا جبارة للمحافظة على مستويات اللغة العربية الأربعة الرئيسـية المتعــارف عليهـا في محاولـة مسنهم لتيسـير التعامل مع المعجم العربي، وإثبات الكلمـات الطارئة على اللغة لإثرائها وإغنائها، وجعلها وافية وملبية للغة العـربي المعاصـر التي تمتلـئ الآن بالمفـردات الأعجميـة والدخيلة والحديثة والمحدثة، الأمر الذي تفطّن له بجمع اللغـة العربيـة بالقـاهرة فأصـدر المعجـم الـوجيز ليلبي حاجة الطلاب حتى مرحلة التعليم الجامعي، والمعجم الوسيط لغير المتخصصين في اللغة العربية، فيما يجري العمل حاليَّا في المعجـم الكبـير الـذي يعـدّ موسـوعة لغوية تغطي اللغة العربية بكافة مستوياها اللغوية دون

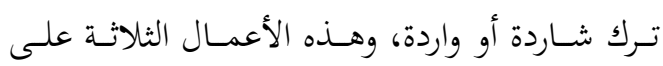
اختلاف أنماطها ومستوى المقصودين بكـلِّ منهـا إلاَّ
ومكلّف الأيام ضدّ طباعها

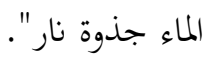

ولعلّ في ذلك أبلغ رٍِّ على من يحاول الفكاك من الجذر اللغوي أو الأصل الثلاثي للكلمة في اللغة

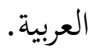

وقد اتفقـت المعـاجم العربيـة قـديمها وحـديثها كما ذكرنا آنفًا في المستوى الصرفي، ولكنها تباينت في معالجة هذا المستوى فالمعاجم الحديثة لم توفِّ هذا الجانب حقه اعتمادًا منها على فطنة المتلقي. وعند تناول المستوى المتعلّق بالفصحى، نجـ أن المعـاجم الحميثـة تنقسـم إلى ثلاثـة أقسـامٍ، القسـم الأول الذي أولى الفصحى في ثوبها التراثي مقامًا رفيعًا ويمثله هنا " متن اللغة " و" المعجم الوسيط "، والقسم الثاني زاوج بين التراثي والمعاصر ويمثله هنـا " المنجد " و " المعجم الوسيط "، والقسم الثالث وهو الذي اهتم اهتمامًا كبيرً بالمعاصر على حساب الفصيح والتراتي ويمثلـه " المعجـم العـربي الأساسي "و " المحيط " و" معجم اللغة العربية المعاصرة ". وعنـــ تنـاول المسـتوى المتعلّـق بالعاميـة فإننـا نلحظ وفرته في كل المعاجم واهتمامها بـه، واحتلاله

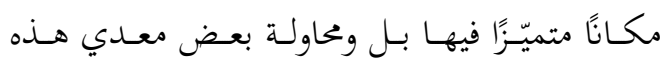
المعاجم لردّه لأصله الفصيح أو تفصيحه، والنص على لى لئ ذلك والإشـارة إليه. وهـو النسـق نفسـه الذذي روعي

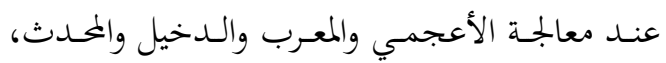
حيـث حرصـت المعـاجم على التبيـهـ إلى كـلِّ منهـا والإشارة إليه مـن خلال النص على ذلك إمّا بالرمز كما في متن اللغة أو بذكر نوع الكلمة كما في المعجم الوسيط فيما اجتهد البعض في تأصيل الكلمة كما في

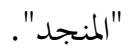

أمـا الألفاظ المحدثة والمعاصـرة فقد زخرت بها المعاجم الثلاثة الأخيرة "المعجم العربي المعاصر والمحيط 
عمـر - رحمـه الله - الـذي قـدّم المعجــم في صـورة إلكترونية. كل ما سبق إضافة إلى إيلاء المصطلحات

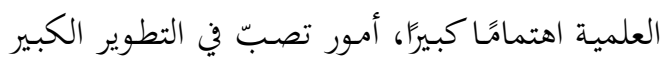

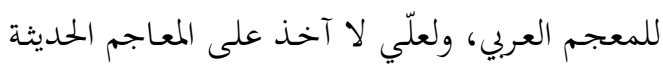

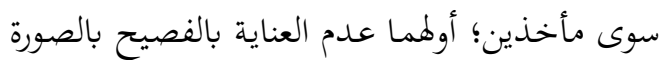

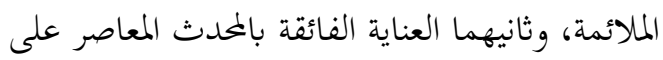
الرغم من المآخذ الكثيرة عليه.
أهـا تربط بـين المستويين الرئيسيين الفصسيح التراثي والعامي المحدث مع الإشـارة إلى الأعجمي والدرخيل والمولّد والمحدث.

بقي أن أشير إلى أنني لم أذكر أمثلة معجمية

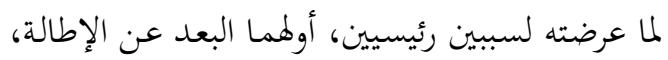
وثانيهما معرفة أغلبية قارئي هذه المعاجم معرفة تغني عن إيراد مثل تلك الأمثلة.

الحخلاصة.

حافظت المعاجم الحديثة على الاعتماد على المصادر :

إبراهيم بن مراد، أسس المعجم المختص اللسانية، بجلة

$$
\text { اللسان العربي ، عدد (^ع) ). }
$$

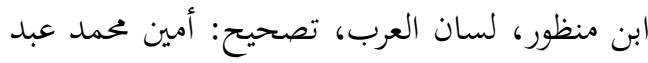
الوهاب، محمد الصادق العبيدي ، دار إحياء التراث العربي، مؤسسة التاريخ العربي، بيروت

$$
\text { . } 99 V-r / b-
$$

أديب اللجمي وآخرون، المحيط (معجم اللغة العربية

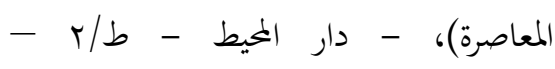

$$
.0199 \varepsilon
$$

المعجم العربي الأساسي، تأليف وإعداد جماعة من كبار اللغويين العرب - المنظمة العربية للتربية

$$
\text { والثقافة والعلوم - لاروس. }
$$

معجم متن اللغة: موسوعة لغوية حديثة، للعلامة اللغوي الشيخ أحمد رضا - بيروت: دار

$$
\text { مكتبة الحياة- }
$$

المعجم الكبير، مجمع اللغة العربية بالقاهرة(صدر منه

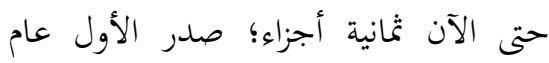

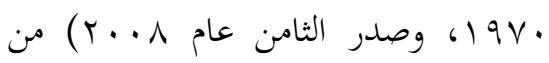
الهمزة إلى الذال.

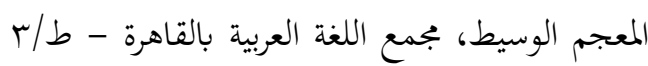

$$
\text { . } 199 \text {. - }
$$
المعجم الوجيز، مجمع اللغة العربية بالقاهرة .
الجذر اللغوي ( الأصل الثلاثي ) للغة العربية، ولم يند

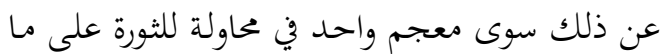
تتميّز بـه العربية. حاولت هذه المعاجم جهـد الطاقة

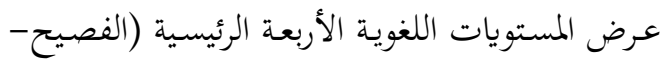
الأعجمي - العامي - المولّد) ولكنها تباينت تباينًا شديدًا في الاهتمام بالفصيح فمن محاول لاستقصائه إلى مقتصر على المستخدم منه والمستعمل فقط، كما

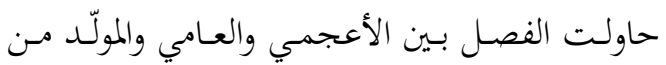

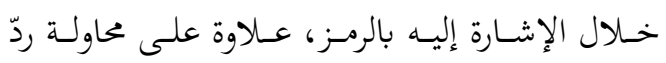

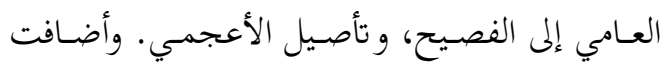

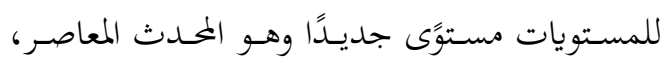
واجتهـدت في إبرازه وتقديمـه للقـارئ وإثبـات شـيوعه

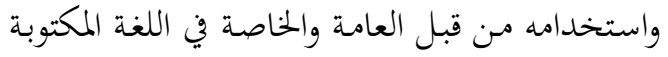

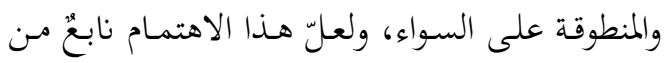

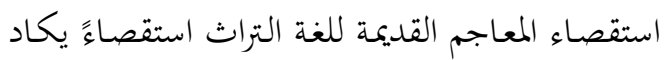

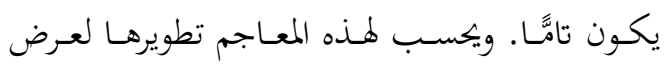
المادة المعجمية في صورة سهلة ومبسطة تبدأ بالأفعال

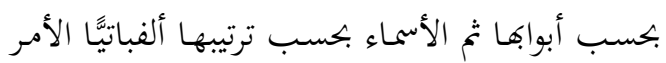
الذذي يسّر البحـث في المعاجم بصـورة كبيرة، وكـان

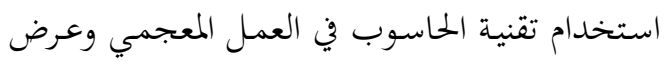

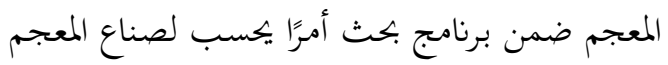
الحـديث وعلى رأسـهم الأستاذ الـدكتور أحمــ مختـار 
Jurnal CMES Volume XI Nomor 1 Edisi Januari - Juni 2018

Program Studi Sastra Arab FIB UNS Surakarta

$$
\begin{aligned}
& \text { المنجِد في اللغة والأعلام، دار المشرق - بيروت - معجم اللغة العبية المعاصرة، أحمد مختار } \\
& \text { عمر - ط/ أح - عأجزاء- القاهرة: عالم } \\
& \text {. } 1991-r v / b
\end{aligned}
$$

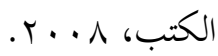

